\title{
Antioxidant Defense Is Increased in Aged Hearts Following Omega-3 Supplementation in the Absence of Changes in Inflammation
}

\author{
S. LENNON-EDWARDS ${ }^{1,2}$, T. A. SCHELLHARDT ${ }^{1}$, J. M. KUCZMARSKI ${ }^{2,3}$ \\ ${ }^{1}$ Department of Behavioral Health and Nutrition, University of Delaware, Newark, DE, USA, \\ ${ }^{2}$ Department of Kinesiology and Applied Physiology, University of Delaware, Newark, DE, USA, \\ ${ }^{3}$ Department of Biological Sciences, University of Delaware, Newark, DE, USA
}

Received August 5, 2014

Accepted October 8, 2014

On-line December 22, 2014

\begin{abstract}
Summary
The purpose of this study was to determine the effect of a 15-week omega-3 rich diet on age-related differences in myocardial antioxidant defense and inflammation. 20 mature (M) (6 mo.) and 20 old (O) (15 mo.) male Fisher 344 rats were assigned to two diet groups: Control (CON) or Fish Oil (FO). Following the diet, animals were sacrificed and left ventricular (LV) heart tissue was harvested for biochemical assays and western blot analysis. No differences were observed in expression of LV interleukin-6 (IL-6) and tumor necrosis factor-a as well as hydrogen peroxide $\left(\mathrm{H}_{2} \mathrm{O}_{2}\right)$ production between MCON and OCON. However, LV catalase protein expression and activity were increased in OCON vs. MCON and accompanied by increased expression of superoxide dismutase (SOD)-1. In contrast, LV IL-6 was lower in MFO vs. old rats, and $\mathrm{LV} \mathrm{H}_{2} \mathrm{O}_{2}$ was decreased in MFO and OFO relative to respective control groups. Protein expression and activity of LV catalase and SOD-1 expression were increased in OFO similarly to OCON, but LV SOD activity was also increased in OFO vs. mature rats. In summary, FO supplementation increased myocardial antioxidant defense in all animals and augmented age-associated increases in antioxidant capacity in the absence of changes in inflammation.
\end{abstract}

\section{Key words}

Aging $\bullet$ Oxidative stress $\bullet$ Omega-3 fatty acids $\bullet$ Inflammation

\section{Corresponding author}

S. Lennon-Edwards, University of Delaware, 201L Health Sciences Complex, Newark, DE 19713, USA. Fax: 011-302-831-4261. E-mail: slennon@udel.edu
The risk of heart disease (HD) increases with age and diet is an important modifiable risk factor that may interact with reactive oxygen species (ROS) and inflammatory markers (de Winther et al. 2005, Devaraj et al. 2007). Diets high in total fat, cholesterol, and particularly saturated fat have been shown through several long-term epidemiological studies to increase the risk of atherosclerosis and subsequent development of HD (Shekelle et al. 1981, Kromhout et al. 1995, Hu et al. 1999, Millen and Quatromoni 2001, Xu et al. 2006). While high intake of atherogenic lipids such as saturated fat are detrimental to the heart (Esrey et al. 1996), polyunsaturated fats, particularly omega-3 fatty acids have been shown to be beneficial (Sinclair 1956, Kromhout et al. 1985, Dolecek and Granditis 1991). Evidence from several observational studies, randomized controlled trials, and animal studies suggest that habitual intake of omega-3 fatty acids reduce the risk of HD (KrisEtherton et al. 2002, Wang et al. 2006, von Schacky and Harris 2007, Serhan and Chiang 2008).

Omega-3 fatty acids are long chain polyunsaturated fatty acids, including eicosapentaenoic acid (EPA) and docosahexaenoic acid (DHA) recommended by several societies including the American Heart Association (Kris-Etherton et al. 2002) and the Guidelines on Cardiovascular Prevention of nine European societies (Graham et al. 2007). The mechanism behind omega-3 related cardioprotection has been attributed to both anti-inflammatory and antioxidant effects. Inflammatory plasma markers including 
interleukin-6 (IL-6) and tumor necrosis factor-alpha $(\mathrm{TNF}-\alpha)$ decrease following EPA and DHA administration (Bhatnagar and Durrington 2003, Ferrucciet et al. 2006, Farzaneh-Far et al. 2009) and circulating levels of the antioxidant glutathione peroxidase increase with omega-3 supplementation (Castillo et al. 2014). In addition, chronic omega-3 supplementation reduces myocardial ischemic injury in rodents as related to reinforcement of endogenous antioxidant defense (Castillo et al. 2014).

Despite the established cardioprotective effects of omega-3 fatty acids, it remains unknown whether supplementation can alter antioxidant defense and inflammation in the hearts of aging rodents. Therefore, the purpose of this study was to determine the effect of a 15-week omega-3 rich diet using (FO) supplementation on age-related differences in myocardial antioxidant defense and inflammation. We hypothesized that FO supplementation would augment antioxidant defense and lower levels of inflammation in the heart of aged animals.

Our experiments were approved by the University of Delaware Animal Care and Use Committee and conducted following the guidelines established by the National Institutes of Health Office of Laboratory Animal Welfare for the use of animals in research. Twenty mature and 20 old male Fisher 344 rats (Harlan Laboratories, Indianapolis, IN) were housed in a temperature controlled facility and maintained on a 12 hour light-dark cycle. Both mature and old animals were randomly assigned to one of two diet groups: (1) control (CON); or (2) fish oil (FO). LabDiet provided the commercial diets (Quakertown, PA). The FO diet (LabDiet 5001 with $10 \%$ Menhaden Fish oil added) contained $2.88 \%$ omega- 3 fatty acids while the CON diet (Modified 5001 with $8 \%$ total fat) contained $0.43 \%$. The Menhaden fish oil contained $30 \%$ omega-3 fatty acids with a 1.16:1 ratio of EPA to DHA. Menhaden fish oil supplementation is a common approach to increase omega-3 content of rodent chow and has been successfully used elsewhere (Hock et al. 1990). The four groups were mature control (MCON), mature fish oil (MFO), old control (OCON), and old fish oil (OFO). Animals were maintained on the diet for 15-weeks and thus were approximately 6 and 15 months when sacrificed. Animals were anesthetized with ketaminexylazine $(100 \mathrm{mg} / \mathrm{kg})$ and sacrificed on the last day of the diet. The heart was removed and the left ventricle (LV) was separated, minced, and homogenized using glass on glass homogenization in cold $100 \mathrm{mM}$ potassium phosphate buffer (1:20 wt/vol; pH 7.4). The homogenate was centrifuged $\left(4^{\circ} \mathrm{C}\right)$ for $10 \mathrm{~min}$ at $400 \mathrm{~g}$. The supernatant was decanted and assayed to determine total protein content using the Bradford Protein assay (Bradford 1976) along with the activities of superoxide dismutase (SOD), catalase (CAT), and hydrogen peroxide $\left(\mathrm{H}_{2} \mathrm{O}_{2}\right)$. SOD activity was measured using a colorimetric assay from Cayman Chemical (Ann Arbor, Michigan), CAT activity was measured using an assay by Aebi (1984) and $\mathrm{H}_{2} \mathrm{O}_{2}$ was measured using the Amplex Red Hydrogen Peroxide/peroxidase kit from Invitrogen (Molecular Probes, Grand Island, NY). All activities were normalized to protein content. Tumor necrosis factoralpha (TNF- $\alpha$ ) and IL- 6 were measured using ELISA kits from R\&D Systems, Inc. (Minneapolis, MN).

To determine the effect of fish oils on induction of myocardial antioxidants, polyacrylamide gel electrophoresis and immunoblotting were performed. Briefly, LV samples from mature and old animals were homogenized and one-dimensional sodium dodecyl sulfate polyacrylamide gel electrophoresis was performed to separate proteins by molecular weight. After separation, proteins were transferred to nitrocellulose membranes (0.45 mm thick, Bio-Rad; Hercules, CA) using the Bio-Rad transblot electrophoretic transfer cell at a constant voltage of $100 \mathrm{~V}$ for one hour. After protein transfer, membranes were blocked overnight at $4{ }^{\circ} \mathrm{C}$ using $5 \%$ nonfat dry milk. Blots were incubated for $1 \mathrm{~h}$ at room temperature using the following antibodies from Santa Cruz Biotechnology (Santa Cruz, CA): mouse monoclonal antibody for SOD-1 (sc-271014), mouse monoclonal antibody for SOD-2 (sc-58425), mouse monoclonal antibody for catalase (sc-271803), mouse monoclonal antibody for GPx-1/2 (sc-133160), and betaactin (sc-47778). Antibodies were then reacted with a rabbit polyclonal secondary antibody to mouse $\mathrm{IgG}$ (ab6728) (Abcam; Cambridge, MA) for one hour at room temperature. Membranes were exposed to chemiluminescent reagents (GE Healthcare) for $1 \mathrm{~min}$ and developed. Bands were normalized to beta-actin and quantification of the bands was performed using Image $J$ software (NIH).

A two-way ANOVA was run to test for an interaction between treatment and age. When a significant main effect was seen, a Bonferroni post-hoc test was run to test for group differences. The level of significance was set at $\mathrm{P}<0.05$ and values are reported as means $\pm \mathrm{SE}$.

At the end of 15 weeks of diet, both aged groups 
Table 1. Markers of oxidative stress and inflammation.

\begin{tabular}{lcccc}
\hline & MCON & MFO & OCON & OFO \\
\hline $\begin{array}{l}\text { Antioxidants } \\
\text { Catalase (U/mg protein) }\end{array}$ & $3.01 \pm 0.33$ & $3.95 \pm 0.24$ & $4.49 \pm 0.52 *$ & $4.25 \pm 0.30^{*}$ \\
SOD (U/mg protein) & $24.1 \pm 1.3$ & $25.4 \pm 1.8$ & $26.9 \pm 1.6$ & $33.8 \pm 3.1^{*} \S$ \\
$\begin{array}{l}\text { Oxidative stress } \\
H_{2} O_{2}(\text { (nM/mg protein) }\end{array}$ & $123.7 \pm 9.2$ & $105 \pm 7.9^{*}$ & $137 \pm 18.7$ & $97.1 \pm 7.7$ 9 \\
Inflammatory markers & & & & \\
IL-6 (pg/mg) & $30.3 \pm 1.85$ & $26.6 \pm 0.67$ & $37.8 \pm 3.8^{*}$ & $37.7 \pm 2.23 \S$ \\
$T N F-\alpha(p g / m g)$ & $10.3 \pm 0.27$ & $13.1 \pm 1.03$ & $11.9 \pm 1.2$ & $11.4 \pm 0.84$ \\
\hline
\end{tabular}

Values are means \pm SE. $\mathrm{N}=10$ in each group. $\mathrm{H}_{2} \mathrm{O}_{2}$, hydrogen peroxide; MCON, mature control; MFO, mature fish oil diet; OCON, old control diet; OFO, old fish oil diet. * $\mathrm{P}<0.05$ from MCON; § $\mathrm{P}<0.05$ from MFO; १ $\mathrm{P}<0.05$ from OCON.

A

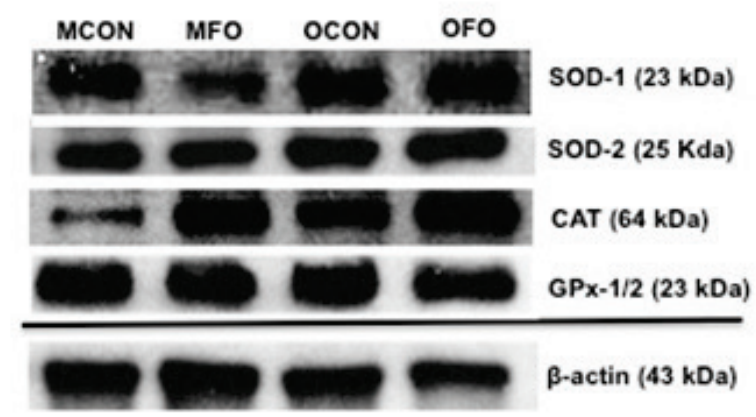

B

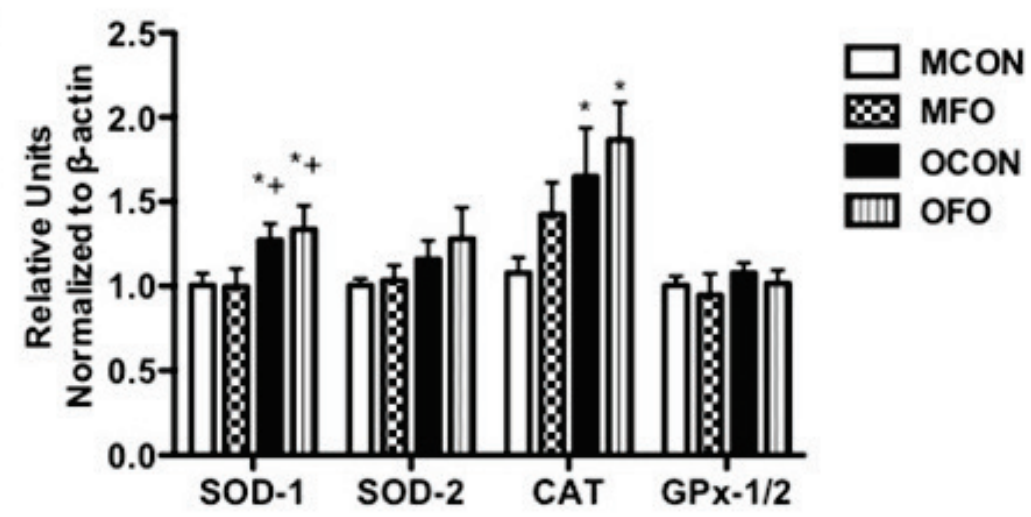

Fig. 1. Representative western blots (A) and quantification (B) of left ventricular antioxidant enzymes for MCON, MFO, OCON and OFO groups. This includes superoxide dismutase-1 (SOD1), superoxide dismutase2 (SOD2), catalase (CAT), and glutathione peroxidase $1 / 2$ (GPx1/2). CAT and SOD1 were increased in the older groups alone. Values are mean $\pm \mathrm{SE}$ and samples were normalized to MCON. * $\mathrm{P}<0.05$ vs. respective $\mathrm{MCON} ;+\mathrm{P}<0.05$ vs. respective MFO. were significantly heavier (OCON: $485 \pm 9 \mathrm{~g}$; OFO: $512 \pm 14 \mathrm{~g})$ than MCON $(448 \pm 4 \mathrm{~g} ; \mathrm{P}<0.05)$ while $\mathrm{MFO}$ $(473 \pm 3 \mathrm{~g})$ was only different from MCON $(\mathrm{P}<0.05)$. Heart mass was lower in the MCON group ( $1.25 \pm 0.01 \mathrm{~g}$ ) relative to the other three groups $(\mathrm{MFO}, 1.30 \pm 0.03 \mathrm{~g}$; OCON, $1.32 \pm 0.03 \mathrm{~g}$; OFO, $1.42 \pm 0.03 \mathrm{~g}$; $\mathrm{P}<0.05)$ which coincided with the differences in total body weight. However, once heart weight was normalized to body weight, no differences were seen among groups.

To determine the effect of the FO diet on markers of inflammation, LV TNF- $\alpha$ and IL-6 were measured. Both are thought to play an important role in cardiovascular disease risk and development (Cesari et al. 2003). No differences were seen in TNF- $\alpha$ concentrations among the groups; however, IL-6 was greater in both aged groups $(\mathrm{P}<0.05)$ with no effect of diet suggesting that the FO supplementation was not sufficient to overcome the aging effects on myocardial inflammation. IL-6 has been shown to be a very reliable inflammatory marker of aging (Johnson 2006) and is increased in healthy, older subjects (Wei et al. 1992). Further, two months of omega-3 supplementation lowered circulating 
IL-6 levels in atherosclerotic patients (Eftekhari et al. 2014). IL-6 was measured in the aged rat heart in this study in the absence of apparent cardiovascular disease, which may explain the discrepancies with previous findings.

Endogenous antioxidant expression and activity was increased in the LV of OCON animals. LV CAT activity was increased in OCON $(\mathrm{P}<0.05$; Table 1) compared to MCON in conjunction with increased protein expression of SOD-1 and CAT (Fig. 1). OFO animals had similar increases in LV CAT expression and activity as well as SOD-1 expression but LV SOD activity was also increased in the $\mathrm{OFO}$ vs. mature rats $\left(\mathrm{P}<0.05\right.$; Table 1). In addition, $\mathrm{H}_{2} \mathrm{O}_{2}$ levels were decreased in both $\mathrm{MFO}$ and OFO relative to their respective control groups. No differences were observed in protein expression of GPx-1/2 between all groups and SOD-2 expression trended similarly as SOD-1 in old animals but did not reach statistical significance $(\mathrm{P}=0.09$ for an effect of age). Overall, endogenous myocardial antioxidant defense was increased with FO supplementation in all animals as indicated by decreased levels of ROS production. FO also augmented ageassociated increases in antioxidant capacity with increased SOD activity and decreased $\mathrm{H}_{2} \mathrm{O}_{2}$ levels (Table 1). Similarly, isolated cardiac myocytes from omega-3 supplemented rats have demonstrated less asynchronous contractile activity in the presence of $\mathrm{H}_{2} \mathrm{O}_{2}$ and had increased SOD expression relative to a control and saturated fat supplemented diet (Dolecek and Granditis 1991).

Our findings are consistent with previous investigation demonstrating increased antioxidant capacity with omega-3 supplementation (Erdogan et al. 2004, Castillo et al. 2014). Eight weeks of DHA and EPA supplementation via gavage providing $1.2 \mathrm{~g} / \mathrm{kg}$ resulted in an increase in antioxidant activity (CAT, SOD1, GPx) in 4-month old rodents (Castillo et al. 2014) while others have shown an increase in SOD and a reduction in oxidative stress in rodents supplemented orally with a fish oil rich capsule containing $0.4 \mathrm{~g} / \mathrm{kg}$ (Erdogan et al. 2004). In this study, only SOD activity became significantly elevated with the FO diet in old animals as compared to controls. Our dose of fish oil was provided in the standard rat chow at $28.8 \mathrm{~g} / \mathrm{kg}$ as opposed to gavage supplementation. This is similar to other studies that have provided diets rich in omega-3 fatty acids in the rodent chow (Hock et al. 1990, Yang et al. 1993). While our omega-3 content was higher, access to chow was not controlled. Based on typical rodent consumption, our animals consumed approximately $0.7 \mathrm{~g}$ of omega- 3 fatty acids each day. Further, the differences in antioxidant expression profiles between studies could be due to the age and/or strain of animals utilized. However this study does not suggest that omega-3 supplementation increases levels of oxidative stress as reported previously (Sinclair 1956).

In summary, the purpose of this study was to determine the effects of 15 weeks of an omega- 3 rich diet on markers of inflammation and endogenous antioxidant defenses in the hearts of mature and old rodents. The primary finding was that a diet rich in omega-3 fatty acids increased myocardial antioxidant defenses in all animals and augmented age-associated increases in antioxidant capacity in the absence of a change in inflammation. Further study is warranted to better characterize whether these changes result in functional changes in the aged heart.

\section{Conflict of Interest}

There is no conflict of interest.

\section{Acknowledgements}

This study was supported by a grant from the University of Delaware Research Foundation.

\section{References}

AEBI H: Catalase in vitro. Methods Enzymol 105: 121-126, 1984.

BHATNAGAR D, DURRINGTON PN: Omega-3 fatty acids: their role in the prevention and treatment of atherosclerosis related risk factors and complications. Int J Clin Pract 57: 305-314, 2003.

BRADFORD MM: A rapid and sensitive method for the quantitation of microgram quantities of protein utilizing the principle of protein-dye binding. Anal Biochem 72: 248-254, 1976.

CASTILLO RL, ARIAS C, FARIAS JG: Omega 3 chronic supplementation attenuates myocardial ischaemiareperfusion injury through reinforcement of antioxidant defense system in rats. Cell Biochem Funct 32: 274-281, 2014. 
CESARI M, PENNINX BW, NEWMAN AB, KRITCHEVSKY SB, NICKLAS BJ, SUTTON-TYRRELL K, TRACY RP, RUBIN SM, HARRIS TB, PAHOR M: Inflammatory markers and cardiovascular disease (The Health, Aging and Body Composition [Health ABC] Study). Am J Cardiol 92: 522-528, 2003.

DE WINTHER MP, KANTERS E, KRAAL G, HOFKER MH: Nuclear factor kappaB signaling in atherogenesis. Arterioscler Thromb Vasc Biol 25: 904-914, 2005.

DEVARAJ S, TANG R, ADAMS-HUET B, HARRIS A, SEENIVASAN T, DE LEMOS JA, JIALAL I: Effect of highdose alpha-tocopherol supplementation on biomarkers of oxidative stress and inflammation and carotid atherosclerosis in patients with coronary artery disease. Am J Clin Nutr 86: 1392-1398, 2007.

DOLECEK TA, GRANDITIS G: Dietary polyunsaturated fatty acids and mortality in the Multiple Risk Factor Intervention Trial (MRFIT). World Rev Nutr Diet 66: 205-216, 1991.

EFTEKHARI MH, ALIASGHARI F, BEIGI MA, HASANZADEH J: The effect of conjugated linoleic acids and omega-3 fatty acids supplementation on lipid profile in atherosclerosis. Adv Biomed Res 3: 15, 2014.

ERDOGAN H, FADILLIOGLU E, OZGOCMEN S, SOGUT S, OZYURT B, AKYOL O, ARDICOGLU O: Effect of fish oil supplementation on plasma oxidant/antioxidant status in rats. Prostaglandins Leukot Essent Fatty Acids 71: 149-152, 2004.

ESREY KL, JOSEPH L, GROVER SA: Relationship between dietary intake and coronary heart disease mortality: lipid research clinics prevalence follow-up study. J Clin Epidemiol 49: 211-216, 1996.

FARZANEH-FAR R, HARRIS WS, GARG S, NA B, WHOOLEY MA: Inverse association of erythrocyte n-3 fatty acid levels with inflammatory biomarkers in patients with stable coronary artery disease: The Heart and Soul Study. Atherosclerosis 205: 538-543, 2009.

FERRUCCI L, CHERUBINI A, BANDINELLI S, BARTALI B, CORSI A, LAURETANI F, MARTIN A, ANDRESLACUEVA C, SENIN U, GURALNIK JM: Relationship of plasma polyunsaturated fatty acids to circulating inflammatory markers. J Clin Endocrinol Metab 91: 439-446, 2006.

GRAHAM I, ATAR D, BORCH-JOHNSEN K, BOYSEN G, BURELL G, CIFKOVA R, DALLONGEVILLE J, DE BACKER G, EBRAHIM S, GJELSVIK B, HERRMANN-LINGEN C, HOES A, HUMPHRIES S, KNAPTON M, PERK J, PRIORI SG, PYORALA K, REINER Z, RUILOPE L, SANS-MENENDEZ S, OP REIMER WS, WEISSBERG P, WOOD D, YARNELL J, ZAMORANO JL: European guidelines on cardiovascular disease prevention in clinical practice: executive summary. Atherosclerosis 194: 1-45, 2007.

HOCK CE, BECK LD, BODINE RC, REIBEL DK: Influence of dietary n-3 fatty acids on myocardial ischemia and reperfusion. Am J Physiol 259: H1518-H1526, 1990.

HU FB, STAMPFER MJ, RIMM E, ASCHERIO A, ROSNER BA, SPIEGELMAN D, WILLETT WC: Dietary fat and coronary heart disease: a comparison of approaches for adjusting for total energy intake and modeling repeated dietary measurements. Am J Epidemiol 149: 531-540, 1999.

JOHNSON TE: Recent results: biomarkers of aging. Exp Gerontol 41: 1243-1246, 2006.

KRIS-ETHERTON PM, HARRIS WS, APPEL LJ: Fish consumption, fish oil, omega-3 fatty acids, and cardiovascular disease. Circulation 106: 2747-2757, 2002.

KROMHOUT D, BOSSCHIETER EB, DE LEZENNE COULANDER C: The inverse relation between fish consumption and 20-year mortality from coronary heart disease. N Engl J Med 312: 1205-1209, 1985.

KROMHOUT D, MENOTTI A, BLOEMBERG B, ARAVANIS C, BLACKBURN H, BUZINA R, DONTAS AS, FIDANZA F, GIAMPAOLI S, JANSEN A, KARVONEN M, KATAN M, NISSINEN A, NEDELIJKOVIC S, PEKKANEN J, PEKKARINEN M, PUNSAR S, RASANEN L, SIMIC B, TOSHIMA H: Dietary saturated and trans fatty acids and cholesterol and 25-year mortality from coronary heart disease: the Seven Countries Study. Prev Med 24: 308-315, 1995.

MILLEN BE, QUATROMONI PA: Nutritional research within the Framingham Heart Study. J Nutr Health Aging 5: 139-143, 2001.

SERHAN CN, CHIANG N: Endogenous pro-resolving and anti-inflammatory lipid mediators: a new pharmacologic genus. Br J Pharmacol 153 (Suppl 1): S200-S215, 2008.

SHEKELLE RB, SHRYOCK AM, PAUL O, LEPPER M, STAMLER J, LIU S, RAYNOR WJ JR: Diet, serum cholesterol, and death from coronary heart disease. The Western Electric study. $N$ Engl J Med 304: 65-70, 1981. 
SINCLAIR HM: Deficiency of essential fatty acids and atherosclerosis, etcetera. Lancet 270: 381-383, 1956.

VON SCHACKY C, HARRIS WS: Cardiovascular benefits of omega-3 fatty acids. Cardiovasc Res 73: 310-315, 2007.

WANG C, HARRIS WS, CHUNG M, LICHTENSTEIN AH, BALK EM, KUPELNICK B, JORDAN HS, LAU J: n-3 Fatty acids from fish or fish-oil supplements, but not alpha-linolenic acid, benefit cardiovascular disease outcomes in primary- and secondary-prevention studies: a systematic review. Am J Clin Nutr 84: 5-17, 2006.

WEI J, XU H, DAVIES JL, HEMMINGS GP: Increase of plasma IL-6 concentration with age in healthy subjects. Life Sci 51: 1953-1956, 1992.

XU J, EILAT-ADAR S, LORIA C, GOLDBOURT U, HOWARD BV, FABSITZ RR, ZEPHIER EM, MATTIL C, LEE ET: Dietary fat intake and risk of coronary heart disease: the Strong Heart Study. Am J Clin Nutr 84: 894-902, 2006.

YANG B, SALDEEN TG, NICHOLS WW, MEHTA JL: Dietary fish oil supplementation attenuates myocardial dysfunction and injury caused by global ischemia and reperfusion in isolated rat hearts. J Nutr 123: 2067-2074, 1993. 